\title{
Minimization of transmission loss using distributed generation approach
}

\author{
Chaantrea Miky Lamin* and Arvind Kumar Singh \\ Department of Electrical Engineering, North Eastern Regional Institute of Science and Technology, \\ Nirjuli 791109, Arunachal Pradesh, India
}

Received: 18 April 2017 / Accepted: 29 November 2017

\begin{abstract}
The goal of this work is to calculate the total loss in the system and minimize this loss by implementation of distributed generation (DG) technology. In this paper, load flow analysis method is followed to calculate the loss in the system in conjunction with the line flows. A simple 5 bus system with the main bus of the substation as the slack bus, three Plant generators at the generator bus and three load buses are taken for analysis. For loss minimization two distributed generators at two load buses are connected. One generator is a synchronous type model and the other is asynchronous type model. We searched for the most economical penetration level and the ratings of the distributed generators are decided by the magnitude of penetration power at each load bus. Using software, power system simulation for electrical (PSSE), the system with and without DG technology is modeled and the output from the PSSE is observed.
\end{abstract}

Keywords: Power loss / line flow / distributed generation (DG) / penetration level (PL) / power system simulation for electrical (PSSE)

\section{Introduction}

The need for energy goes on increasing day by day but the supply of energy is very limited. The main reason for the energy crisis is that we have not able to harvest all the available energy in the nature due to technical generation problem or we can say we have not get enough ideas how to generate energy for our needs and consumptions [1]. Power losses appear in every part of our power system like in generation, transmission and distribution as well as in consumption process. Starting from the generation, the inputs such as petroleum, natural gas and coal in case of thermal power plant; nuclear fuel as in case of nuclear power plant were combusted to produce heat to convert water into steam to run the prime mover of the generators. In the process of combustion a large amount of energy is lost in the form of heat. Even in the case of hydropower plant there is a loss in the transformation process due to technical inefficiency. After generation; electricity output is transmitted using transmission lines usually high or medium voltage above $132 \mathrm{kV}$. In transmission lines the main causes of electricity loss are the technical factors, the climatological factors and the geographical conditions. Corona loss also occurs when the line to line voltage exceed

\footnotetext{
* e-mail: chaantreamikylamin@gmail.com
}

the disruptive critical voltage i.e. the potential difference between the conductors, at which the electric field intensity at the surface of the conductor exceed the critical value [2]. Radiation loss occurs when the magnetic lines of force about a conductor do not return to the conductor when the cycle alternates. High frequency radiations like X-rays, gamma rays, ultraviolet rays called ionizing radiations can remove an electron from an atom or molecule. Low frequency radiations are called as non ionizing radiation and they have enough energy to move an atom in a molecule [3]. In case of distribution losses the main causes are both technical and non technical factors [4,5]. This is because in distribution, besides transportation, there are several operations like tapings, metering and controls. These operations consumed energy which results into power loss.

\section{Line flows}

In order to find the loss in each branch i.e. from one bus to the other bus we need to calculate the line flows from one branch to the other in both directions. The line flows equation is given as follow [6]:

The power flow at bus $p$ from bus $p$ to bus $q$ is given as

$$
I_{p q}=\left(V_{p}-V_{q}\right) Y_{p q}+V_{p} \frac{Y^{\prime}}{2}
$$




$$
\text { Now, } \begin{aligned}
P_{p q}-j Q_{p q} & =V_{p} I_{p q}^{*}, \\
& =V_{p}\left[\left(V_{p}^{*}-V_{q}^{*}\right) Y_{p q}^{*}+V_{p}^{*} \frac{Y^{\prime}}{2}\right], \\
\text { Or, } P_{p q}-j Q_{p q} & =V_{p}\left(V_{p}^{*}-V_{q}^{*}\right) Y_{p q}^{*}+V_{p} V_{p}^{*} \frac{Y^{\prime}}{2}
\end{aligned}
$$

Here $P_{p q}$ is the real power flow from bus $p$ to $q$ and $Q_{p q}$ is the reactive power flow from $q$ to $p$.

Similarly, at bus $q$ the power flow from bus $q$ to $p$ is given as:

$$
P_{q p}-j Q_{q p}=V_{q}\left(V_{q}^{*}-V_{p}^{*}\right) Y_{q p}^{*}+V_{q} V_{q}^{*} \frac{Y^{\prime} *}{2},
$$

The total power loss, $P_{\text {TLoss }}$

$$
\begin{aligned}
=\sum P_{q p}-j Q_{q p} \quad p=1,2, \ldots, n \\
q=1,2, \ldots, n
\end{aligned}
$$

\subsection{Admittance matrix}

To convert impedance into admittance we used the following formula:

$$
\text { Admittance, }\left(Y_{p q}\right)=\frac{1}{\text { impedance, } Z_{p q}},
$$

where, $p$ and $q$ are bus number $=1,2, \ldots, n$

Admittance matrix $[Y]=\left[\begin{array}{cccccl}Y_{11} & Y_{12} & \ldots & \ldots & \ldots & Y_{1 n} \\ Y_{21} & Y_{22} & \ldots & \ldots & \ldots & Y_{2 n} \\ \cdot & . & \ldots & \ldots & \ldots & . \\ \cdot & . & \ldots & \ldots & \ldots & . \\ Y_{n 1} & Y_{n 2} & \ldots & \ldots & \ldots & Y_{n n}\end{array}\right]$

\section{Distributed generators}

Distributed generation (DG) is a small-scale generation which is not directly connected to main transmission system and is not centrally dispatched [7]. It can be of great advantage in isolated locations where central generation is a challenge and where grid extension is difficult. It can be fed back into the grid in an integrated way [8].

The available size of DG per module can be as little as $1 \mathrm{~kW}$ to as high as $250 \mathrm{MW}$. Depending on the technology size, DGs may be classified into [9]:

- micro $(1 \mathrm{~W}-5 \mathrm{~kW})$;

- small (5 kW-5 MW);

- medium (5-50 MW);

- large (50-300 MW).

Based on their electrical output characteristics distributed generators can be classified into three classes of DG technologies are as follows [10]:

- synchronous generator technologies (SGTs);
- induction generator technologies (IGTs);

- asynchronous generator based technologies (AGTs).

SGTs can maintain their terminal voltage by varying the amount of reactive power they generate. So they are able to operate at varying power factors [11].

IGTs required reactive power to magnetize their rotors and this can be supplied either by the grid or capacitor banks [11].

AGTs use power electronic devices as interface to the grid. Power electronic devices invert DC power generated to $\mathrm{AC}$ power at the required grid frequency and voltage [11].

\subsection{Synchronous generator technologies (SGTs)}

SGTs are modeled as generators with constant terminal voltage with known real power generation and known reactive power limits. A constant terminal voltage could be achieved by varying the reactive power generated. This model incorporates the variable power factor model of Gonzalez-Longatt (2007) and constant voltage model of Teng (2007). For a given real power $\left(P_{S G T}\right)$ and terminal voltage $\left(V_{S G T}\right)$ the reactive power $\left(Q_{S G T}\right)$ was allowed to vary as [11]:

$$
-0.75 P_{S G T} \leq Q_{S G T} \leq 0.75_{P S G T} .
$$

When SGT is implement on a network the $P Q$ bus where the SGT is to be connected gets converted to a PV bus. If $P_{l i}$ is the real power consumed by the load at bus $i$ and $Q_{l i}$ is the reactive power consumed by the load at the same bus, on connecting the synchronous generator technology, the new real power $\left(P_{n l i}\right)$ and new reactive power $\left(Q_{n l i}\right)$ consumed at bus $i$ can be determined by [11]:

$$
\begin{gathered}
P_{n l i}=P_{l i}-P_{S G T}, \\
Q_{n l i}=Q_{l i}-Q_{S G T} .
\end{gathered}
$$

\subsection{Induction generator technologies (IGTs)}

In IGT the reactive power absorbed from the grid can be derived from the equivalent circuit of an induction generator as follows [11]:

$$
\begin{aligned}
Q & =V^{2} \frac{X_{c}-X_{m}}{X_{c} X_{m}}+X \frac{V^{2}+2 R P}{2\left(R^{2}+X^{2}\right)} \\
& -X \frac{\sqrt{\left(V^{2}+2 R P\right)^{2}-4 P^{2}\left(R^{2}+X^{2}\right)}}{2\left(R^{2}+X^{2}\right)},
\end{aligned}
$$

where, $X_{m}$ is the magnetizing reactance; $X_{c}$ is capacitor banks reactance; $X$ is the sum of the rotor and stator leakage reactance; $R$ is the sum of the rotor and stator resistances; $V$ is the voltage; $P$ is the real power generated and it is positive when it is injected into the grid.

By considering only the first two derivatives of the McLaurin approximation of equation (11) and neglecting resistance $R$, then the reactive power absorbed by an IGT can be approximated as:

$$
Q=-Q_{0}-Q_{1 *} P-Q_{2 *} P^{2}
$$


Hence, for a given generated real power, $P$ and machine parameters, $X_{c}, X_{m}$, and $X$, the reactive power consumed by the induction based generator technologies can be obtained as:

$$
Q_{I G T} \approx V 2 \frac{X_{c}-X_{m}}{X_{c} X_{m}}+\frac{X}{V^{2}} P^{2} .
$$

On implementation of IGT the voltage at $P Q$ buses are unknown until convergence of a load flow algorithm. So equation (9) cannot be used in a straight forward manner to determine the reactive power consumed at the $P Q$ Bus. The reactive power consumed by the induction generator can be determined as follow [11]:

- the load flow of the test network with no IGT connected is determined;

- the voltage obtained at the bus where the generator is to be connected is used in solving equation (9);

- new active power $\left(P_{n l i}\right)$ and new reactive power $\left(Q_{n l i}\right)$ are determined from the pre-determined $P$ and calculated $Q_{I G T}$ in equation (9) as follows:

$$
\begin{aligned}
& P_{n l i}=P_{l i}-P_{I G T}, \\
& Q_{n l i}=Q_{l i}-Q_{I G T} .
\end{aligned}
$$

\subsection{Asynchronous generator based technologies (AGTs)}

In AGT by varying the triggering angles for the power electronic interfaces of AGT, it can be made to operate at varying power factors. For a given generated real power $\left(P_{A G T}\right)$ and power factor $(\cos \phi)$ the reactive power generated is given as [11]:

$$
Q_{A G T}= \pm \sqrt{P_{A G T} 2-\left(\frac{1}{(\cos \phi)^{2}}-1\right)},
$$

If $\cos \phi \geq 0, Q_{A G T} \geq 0$. Otherwise, $Q_{A G T}<0$.

When connect to a network, AGT is modeled as a negative loads. If $P_{l i}$ is the real power consumed by the load at bus $i$ and $Q_{l i}$ is the reactive power consumed by the load at the same bus, on connecting the asynchronous generator technology, the new real power $\left(P_{n l i}\right)$ and reactive power $\left(Q_{n l i}\right)$ consumed at bus $i$ can be written as:

$$
\begin{gathered}
P_{n l i}=P_{l i}-P_{A G T}, \\
Q_{n l i}=Q_{l i}-Q_{A G T} .
\end{gathered}
$$

\subsection{Penetration level}

Penetration level $(P L)$ refers to how much of the real power demand of the network is met by the DG technologies. It can be mathematically represented as [11]:

$$
P L=\frac{P_{D G}}{P_{\text {load }}} \times 100 \%,
$$

$P L$ of $0 \%$ represents that the load demand is totally met by the grid and a $P L$ of $100 \%$ means that the load demand is supplied entirely by the DG Technologies. $P_{D G}$ is the output of the DGs.

\section{Problem formulation}

The aim of the proposed work is to calculate and reduce transmission power loss by using DG technology.

\subsection{Algorithm followed for loss reduction using DG:}

Step 1 : Read the input data.

- Line data (impedance, shunt reactance) [Appendix A].

- Bus data (voltage, active and reactive load) [Part 5].

Step 2 : Calculate the admittance matrix of the system [Eqs. (6), (7)].

Step 3 : Calculate power loss by Gauss-Seidel iteration method [Eq. (3)].

Step 4 : Simulate the network in PSSE.

Step 5 : Implement DGs at bus 2 and bus 3 [Fig. 2].

Step 6 : Input the $P L$ [Appendix A].

Step 7: Input the ratings of distributed generators [Appendix A].

Step 8 : Calculate their per unit impedance.

Step 9 : Calculate the new admittance matrix [Eqs. (6), (7)].

Step 10 : Calculate power loss by Gauss-Seidel iteration method [Eq. (5)].

Step 11 : Compare the losses with and without distributed generators.

- If the losses are less than without distributed generators, then simulate with PSEE. And stop.

- If the losses are more than without distributed generators or not economical compare to distributed generator size, PL is changed. And step 6 is repeated.

Step 12 : Calculate the overall reduction of losses considering the DGs rating.

Step 13 : Integrate the selected DGs size to the network and simulate using PSSE under the selected PL.

Step 14 : Calculate the loss reduction percentage.

\section{System under study}

Power grid Corporation of India Ltd. Nirjuli was commission on 2nd June 1991. The transformation capacity of this Sub-Station is 100 MVA. There are 2 power transformers each of $50 \mathrm{MVA}$ transformation capacities. It draws the power from Ranganadi hydro electric power plant (RHEP), through $132 \mathrm{kV}$ transmission line and also from Gohpur substation through Gohpur-ltanagar transmission. There are 3 generators at RHEP bus each with a generating power of $135 \mathrm{MW}$. There are three outgoing $33 \mathrm{kV}$ feeder namely, $33 \mathrm{kV}$ AP Feeder-1 for Itanagar, $33 \mathrm{kV}$ AP Feeder-2 for Banderdewa and $33 \mathrm{kV}$ AP Feeder-3 for Nirjuli. The total load is around $29 \mathrm{MW}$ and 21.58 MVAR after the transformation process and the Gohpur bus take around $40 \mathrm{MW}$ and 29.76 MVAR when RHEP line is in good condition. The maximum load through the Power grid Corporation of India ltd. Substation, Nirjuli is $85 \mathrm{MW}$ and 


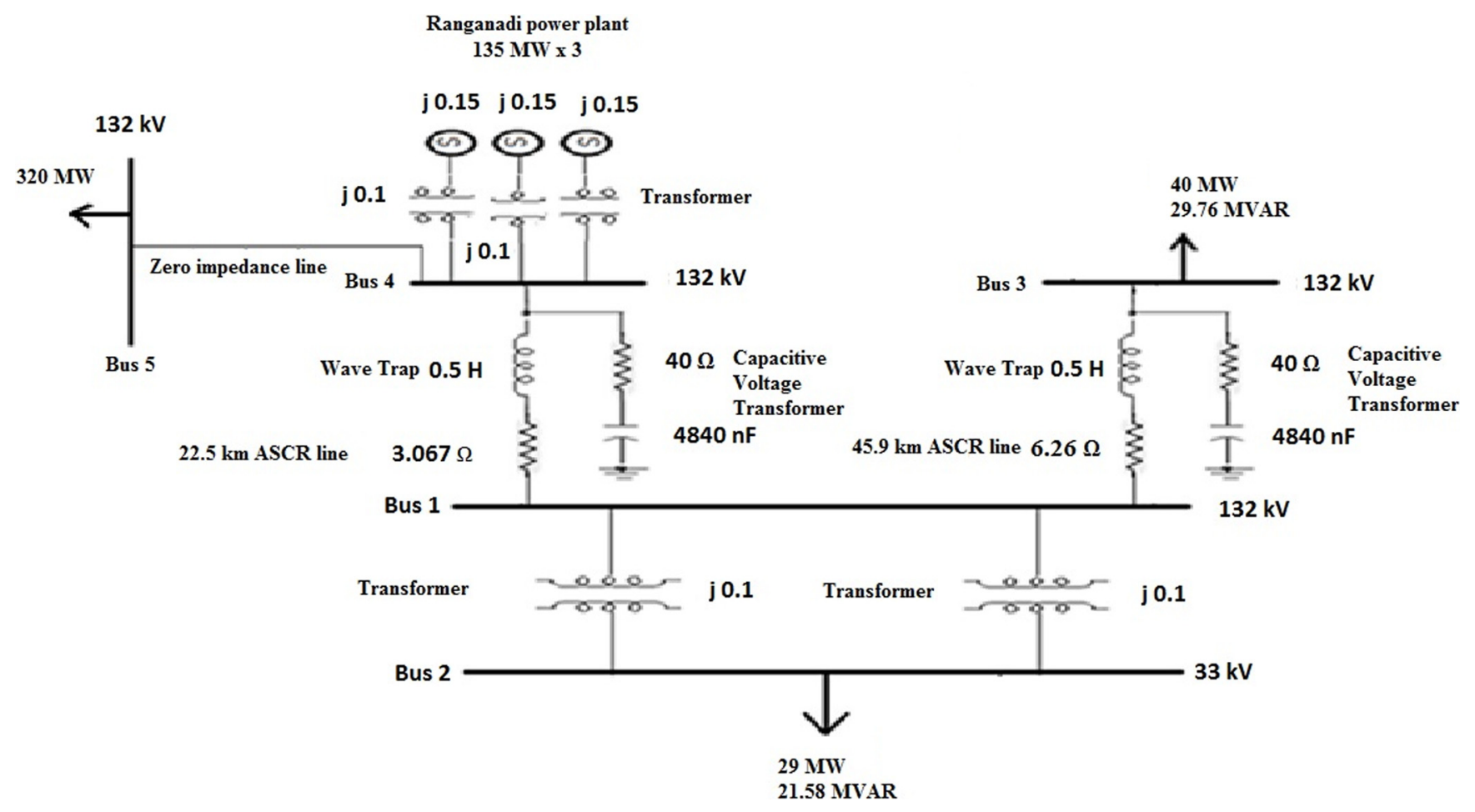

Fig. 1. Single line diagram of actual parameter of the network without DG.

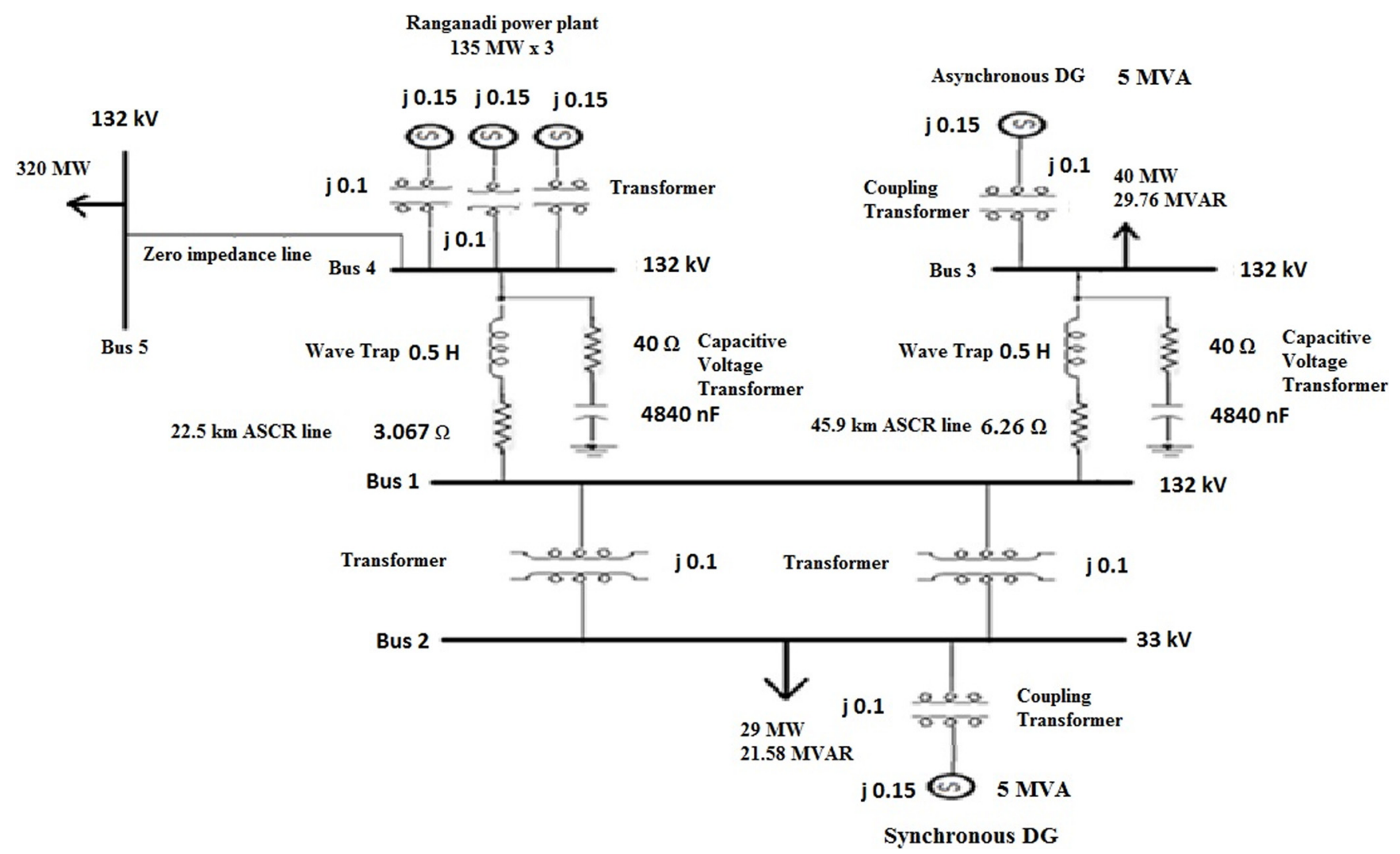

Fig. 2. Single line diagram of the system parameters after implementation of DG. 
Table 1. Losses obtained by Gauss-Seidel calculation method for the system.

\begin{tabular}{|c|c|c|c|c|c|c|}
\hline \multirow{2}{*}{$\begin{array}{l}\text { Sl. } \\
\text { no. }\end{array}$} & \multirow{2}{*}{$\begin{array}{l}\text { Line flows } \\
\text { from bus }\end{array}$} & \multirow{2}{*}{$\begin{array}{l}\text { Line flows } \\
\text { to bus }\end{array}$} & \multicolumn{2}{|c|}{ Without distributed generators } & \multicolumn{2}{|c|}{ With distributed generators } \\
\hline & & & $\begin{array}{l}\text { Real power } \\
\text { in MW }\end{array}$ & $\begin{array}{l}\text { Reactive power } \\
\text { in MVAR }\end{array}$ & $\begin{array}{l}\text { Real power } \\
\text { in MW }\end{array}$ & $\begin{array}{l}\text { Reactive power } \\
\text { in MVAR }\end{array}$ \\
\hline 1 & 1 & 2 & -28.95 & -22.80 & 26.03 & -67.13 \\
\hline 2 & 2 & 1 & 28.95 & 21.45 & -26.04 & 10.68 \\
\hline 3 & 1 & 3 & -53.93 & -18.95 & 33.86 & 19.76 \\
\hline 4 & 3 & 1 & 54.41 & -36.65 & -32.52 & -43.49 \\
\hline 5 & 1 & 4 & 23.69 & -11.01 & 23.69 & -11.01 \\
\hline 6 & 4 & 1 & -22.25 & -22.13 & -22.25 & -22.13 \\
\hline 7 & Losses & & 1.92 & 90.09 & 2.77 & 37.55 \\
\hline
\end{tabular}

Table 2. Output data from PSSE for the system without DG.

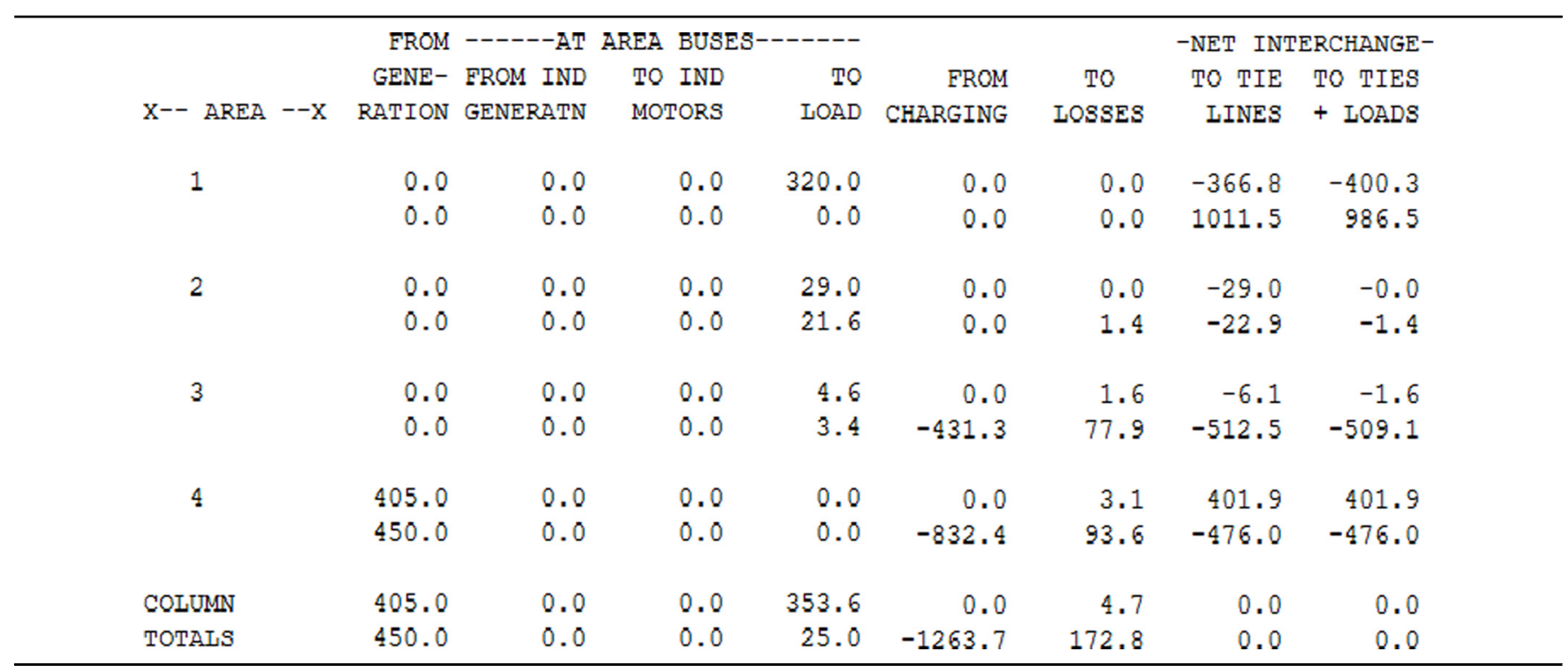

around $320 \mathrm{MW}$ are dispatched to other substations e.g. Chimpu and Lekur through nahalagun-dikrong transmission line (NDTL). Figure 1 shows single line diagram of the actual parameter of the system, the value of which is shown in the Appendix A. The value of the system parameters are converted into per unit impedance and admittance with the base of $150 \mathrm{MVA}, 132 \mathrm{kV}$ and $33 \mathrm{kV}[6,12]$.

The network busses are numbered as follows:

- main substation bus as slack bus (Bus 1);

- $33 \mathrm{kV}$ Nirjuli bus (Bus 2);

- Gohpur bus (Bus 3);

- RHEP bus (Bus 4);

- NDTL bus (Bus 5).

After calculation we adopted a DG $P L$ of $10 \%$, which is found economical, at bus 2 and bus 3 and the size of distributed generators is 5 MVA each. Distributed generator at bus 2 is taken to be a hydro power plant [13] which is a synchronous model type and distributed generator at bus 3 is taken to be a thermo-photovoltaic power plant $[14,15]$ which is an asynchronous model type. Figure 2 shows the parameter of the modified system after implementation of DG technology, the rating and impedance of which is shown in Appendix A.

\section{Results and outputs}

See Tables 1-3.

\section{Conclusion}

Using Gauss-Seidel method, the real power loss in the system is $1.92 \mathrm{MW}$ and the reactive power loss is 90.09 MVAR (Tab. 1) which amount 90.10 MVA. After the implementation of DG the real power loss is found to be $2.77 \mathrm{MW}$ and the reactive power loss is $37.55 \mathrm{MVAR}$ (Tab. 1), the magnitude of losses is $37.65 \mathrm{MVA}$. The reduction in power loss is $58.21 \%$. Although there is a bit 
Table 3. Output data from PSSE for the system with DG.

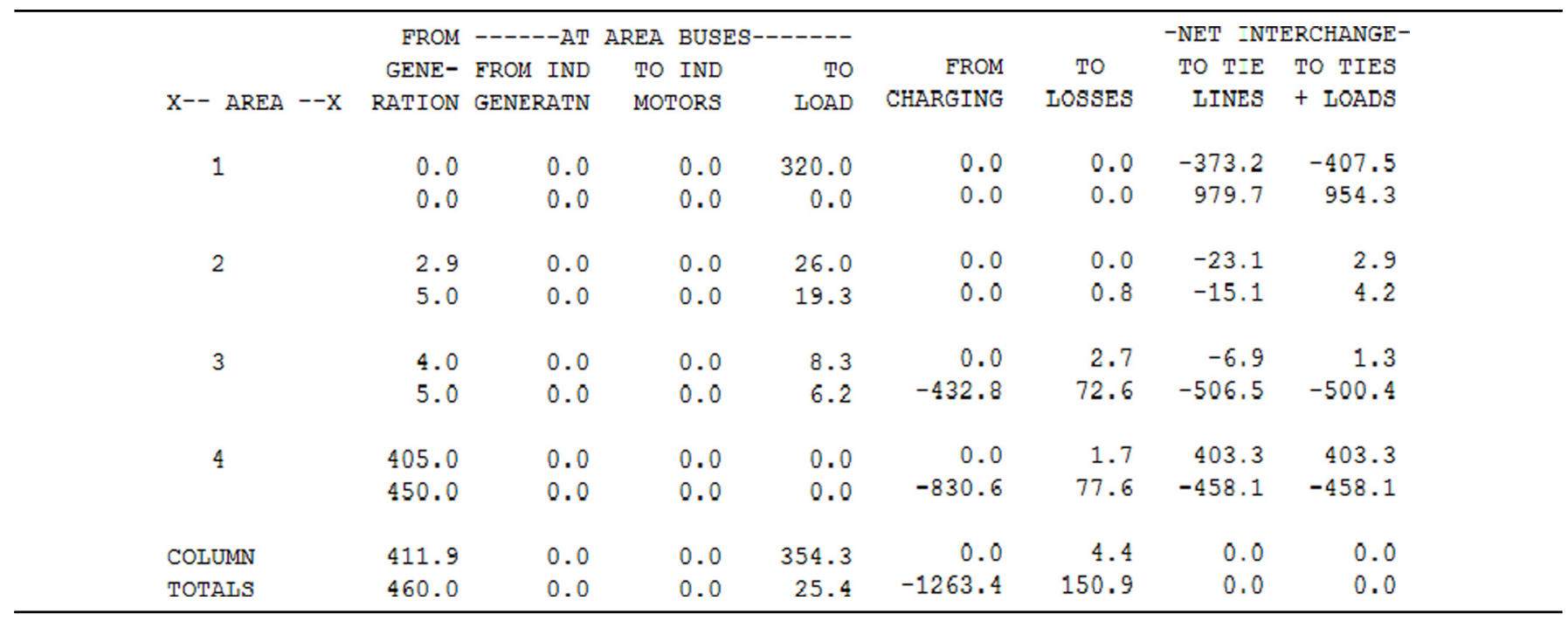

increase in real power loss, the overall loss decreased significantly.

From the output of PSSE simulation software, the real power loss of the system is $4.7 \mathrm{MW}$ and the reactive power loss is 172.7 MVAR (Tab. 2) which amount 172.76 MVA. After the implementation of DG technology, the real power loss is $4.4 \mathrm{MW}$ and the reactive loss is $150.9 \mathrm{MVAR}$ (Tab. $3)$, the magnitude of losses is $150.96 \mathrm{MVA}$. There is $12.61 \%$ reduction in power loss.

We obtained a reduced magnitude of overall loses after implementation of DG. Base from the amount of losses in both the cases, we found that the system performed better when DG is implemented.

\section{References}

1. M. Kumar, A. Kumar, K.S. Sandhu, PV-WT based distribution generator location minimizing transmission loss in Pool/Bilateral electricity market model, Procedia Technol. 25, 692-701 (2016)

2. T.L. Alumona et al., Overview of Losses and Solutions in Power Transmission Lines (2014) Vol. 4

3. International Agency for research on 2015 cancer, IARC monograph on evaluation of carcinogenic risk to human, Vol. 80 , part 1.

4. R. Jimenz, T. Serrisky, K. Mercado, Power Lost: Sizing Electricity Loses in Transmission and Distribution System in Latin America and Caribbean, 2014

5. J. Parmar, Total Losses in Power Distribution and Transmission Lines-Part 1 (2013) https://electricalnotes.wordpress. com
6. J.B. Gupta, in Switch Gear and Protection, 2nd edn. (SK Kataria and Sons, New Delhi, 2004) pp. 29-608

7. H.A. Attia, Z.H. Osman, M. El-Shibini, A.A. Moftah, An assessment of distributed generation impacts on distribution networks using global performance index, Nat. Sci. 8, 150 $158(2010)$

8. C.T. Borges, D.M. Falcao, Impact of distributed generation allocation and sizing on reliability, losses and voltage profile, in IEEE Bologna Power Tech, Conference Bologna (Italy, 2003), pp. 1-5

9. T. Ackermann, G. Andersson, L. Soder, Distributed generation: a definition, Electr. Power Syst. Res. 57, 195-204 (2001)

10. C.J. Mozina, A Tutorial on the Impact of Distributed Generation (DG) on Distribution Systems (2010) p 19.

11. A.S.O. Ogunjuyigbe, T.R. Ayodele, O.O. Akinola, Impact of distributed generators on the power loss and voltage profile of sub-transmission network, J. Electr. Syst. Inf. Technol. 3, 94-107 (2016)

12. C.L. Wadhwa, in Electrical Power System, 4th edn. Chapter 18 (New Age International, Chennai, 2005)

13. P. Cunningham, I. Woofenden, Micro-hydro electric system, Home power 117, (2007) Viewed on 2016/08, https://www. homepower.com

14. IEEE Standard for Interconnecting Distributed Resources with Electric Power Systems Standards Coordinating Committee 21, Sponsor by (Fuel Cells, Photovoltaics, Dispersed Generation, and Energy Storage), Approved 2003/12/06, Reaffirmed 2008/25/09

15. T.J. Coutts, An overview of thermophotovoltaic generation of electricity, NREL/CP-520-26904, in 11th International Photovoltaics Science and Engineering Conference (PVSEC11) (1999) 


\section{Appendix A}

Table A.1. Network data used for calculations.

\begin{tabular}{lll}
\hline Serial no. & Components & Parameter value \\
\hline 1 & ASRC conductor (panther) & Resistance $=0.1363 \Omega / \mathrm{km}$ \\
2 & Wave trap & Inductance $=0.5 \mathrm{H}$ \\
& Resistance $=40 \Omega$, \\
3 & Capacitive voltage transformer & $50 \mathrm{~Hz}$ \\
4 & Frequency & $15 \%$ \\
5 & Generator impedance $(3 \times 135 \mathrm{MW}), 150 \mathrm{MVA}$ & $10 \%$ \\
6 & Transformer impedance $(3 \times 150 \mathrm{MVA})$ & $10 \%$ \\
7 & Transformer impedance $(2 \times 50 \mathrm{MVA})$ & $22.5 \mathrm{~km}$ \\
8 & RHEP- PGCIL line (Bus 3 to Bus 1$)$ length & $45.9 \mathrm{~km}$ \\
9 & Gohpur- PGCIL line (Bus 4 to Bus 1$)$ length & $15 \%$ \\
10 & Distribution generator $(2 \times 5 \mathrm{MVA})$ & $10 \%$ \\
11 & Coupling transformer $(2 \times 5 \mathrm{MVA})$ & $10 \%$ \\
12 & PL & Neglected \\
13 & Isolator impedance & Neglected \\
14 & Circuit breaker impedance & Neglected \\
15 & LA capacitance & Neglected \\
16 & CT and PT impedance (metering and control loss) &
\end{tabular}

Cite this article as: Chaantrea Miky Lamin, Arvind Kumar Singh, Minimization of transmission loss using distributed generation approach, Int. J. Simul. Multidisci. Des. Optim. 9, A1 (2018) 